\title{
Comment on Lessons from failure: neurosurgical outreach in Managua, Nicaragua, by Jandiala et al.
}

\author{
Richard Hayward ${ }^{1}$ \\ Published online: 22 April 2021 \\ (C) The Author(s), under exclusive licence to Springer-Verlag GmbH Germany, part of Springer Nature 2021
}

There is an all too often overlooked moral imperative for those working in the so-called developed world to disseminate their knowledge and expertise to those communities in which the resources we take for granted are unavailable.

When it comes to surgery, there are two basic models - the "Parachute" approach in which a team of super-specialists beams in for a few days and operates on a select group of patients in a flamboyant display of technical skills before vanishing back into the clouds from which they had descended. The other less glamourous but with more lasting benefits is when the emphasis is on the education of local health care providers in the management of what they have identified as their most urgent needs.

In this brief horror story, the authors describe their attempt to assist the limited neurosurgical community in Managua, Nicaragua, in the management of paediatric and adolescent hydrocephalus by introducing them to endoscopic techniques aimed at reducing reliance on expensive and infection/ blockage-prone shunts. This was to be accomplished in three missions but only the first (in which 11 patients were operated) took place. The second fell victim to local political turmoil. "Upon arriving at the institution, the visiting team was told by the new administration that they were not allowed to operate or teach, and were immediately directed to the airport to leave the country out of fear that a geopolitical crisis could ensure."

Richard Hayward

richard.d.hayward@gmail.com

1 Department of Paediatric Neurosurgery, Great Ormond Street Hospital for Children, London, UK
The authors draw three lessons from their experience. One - make sure the hospital administrators and the doctors are communicating with each other. That this was not the case became only too painfully obvious at the onset of mission 2 . The second can be crudely described as "Put a finger to the local geo-political wind," while number 3 emphasises the importance of video and digital communications.

And their conclusion? "When selecting a site for a medical initiative, extensive communication with local citizens, a political expert of the region in the US, and an official in the host country should take place. US News sources should also be routinely monitored to assess the geopolitical stability of the site."

The authors are to be commended on their ambition and the carefully thought-out stages of outreach with which they planned to accomplish it. But did they really have no idea of what might have lain in store from them as they set out on their second mission? This was 2018 after all—a period during which relationships between the USA and South America could hardly be described as stable. I would have liked to have detected at least a hint of self-reflection (and contrition?) in their account of what in retrospect could be described as, at the very least, a worrying display of naivety.

But none of this is to detract from the worthiness of an attempt which should stand as a commendable example to the neurosurgical community at large.

We are now in the age of Covid with its near-universal impediment to any physical form of outreach to the very countries that need it most. Hopefully, this will spur on the development of more sophisticated ways of fulfilling the authors' third message - to accelerate the development of learning at a distance through video/digital technology.

Publisher's note Springer Nature remains neutral with regard to jurisdictional claims in published maps and institutional affiliations. 